\title{
Spontaneous endocrine cure of gigantism due to pituitary apoplexy
}

\author{
O ARISAKA, R HALL, I A HUGHES
}

\begin{abstract}
An 11 year old, tall boy presented with symptoms typical of pituitary apoplexy. A large necrotic and haemorrhagic tumour was removed, which was shown to be an adenoma secreting growth hormone and prolactin. Subsequent treatment comprised cranial irradiation and hormone replacement. Eighteen months after operation growth was static and plasma growth hormone and prolactin concentrations were undetectable.

Treatment of pituitary apoplexy should comprise excision of the tumour and postoperative irradiation; such treatment after early recognition of the condition offers the best chance of preserving normal pituitary function in children with gigantism.
\end{abstract}

\section{Introduction}

Pituitary apoplexy is caused by infarction or haemorrhage, or both, into a pituitary tumour. The symptoms and signs are usually typical, with the sudden onset or worsening of headache, vomiting, visual deterioration, fever and drowsiness, and coma. There may be evidence of previous pituitary dysfunction such as acromegaly, Cushing's syndrome, or hyperprolactinaemia. ${ }^{1}$ The condition commonly presents as a neurosurgical emergency requiring prompt decompression of the pituitary mass to restore vision. This decompression not only relieves pressure on vital intracranial structures but also confirms the presence

\footnotetext{
Department of Child Health, Welsh National School of Medicine, Heath Park, Cardiff CF4 4XN

O ARISAKA, MD, research fellow

I A HUGHES, MD, MRCP, senior lecturer

Department of Medicine, Welsh National School of Medicine R HALL, MD, FRCP, professor

Correspondence to: Dr I A Hughes.
}

of a haemorrhagic necrotic tumour characteristic of the condition. Pituitary apoplexy has been reported as occurring in $5-10 \%$ of patients with pituitary tumour. ${ }^{2}$

We report results of clinical and endocrine studies in a tall boy who developed symptoms of acute raised intracranial pressure after pituitary apoplexy associated with a pituitary adenoma secreting both growth hormone and prolactin.

\section{Case report}

An 11 year old boy presented with severe frontal headache, vomiting, fever, and blurred vision of 12 days' duration. Intermittent headaches over several months had been treated as migraine. Rapid growth had started at age 8 , but the rate had slowed during the previous year. On examination he was tall $(169 \mathrm{~cm} ;+3 \mathrm{SD}$ over the normal mean), but there were no obvious signs of acromegaly. He was pale, febrile, yet fully conscious. He had decreased visual acuity, bilateral optic atrophy, and a bitemporal hemianopia. Blood pressure was normal. There was no gynaecomastia, but he had galactorrhoea on expression; he was in early puberty. The cerebrospinal fluid was normal.

Radiography of the skull showed an enlarged pituitary fossa; computed tomography showed a mass that enhanced homogeneously, filling much of the pituitary fossa, with some suprasellar extension. Preoperative serum thyroxine concentration was $57 \mathrm{nmol} / \mathrm{l}(4 \cdot 4 \mu \mathrm{g} /$ $100 \mathrm{ml}$ ) (normal $60-150 \mathrm{nmol} / 1(4 \cdot 7-11 \cdot 7 \mu \mathrm{g} / 100 \mathrm{ml})$ ); triiodothyronine $1.2 \mathrm{nmol} / 1(0 \cdot 8 \mathrm{ng} / \mathrm{ml})$ (normal $1 \cdot 2-3 \cdot 1 \mathrm{nmol} / 1(0 \cdot 8-2 \cdot 0 \mathrm{ng} / \mathrm{ml})$ ); thyroid stimulating hormone $<2.5 \mathrm{mU} / 1$ (normal $<5 \mathrm{mU} / 1$ ); diurnal plasma cortisol $<28 \mathrm{nmol} / 1(<1.0 \mu \mathrm{g} / 100 \mathrm{ml})$; random serum growth hormone during sleep $1.8 \mathrm{mU} / 1$; and plasma testosterone $1.4 \mathrm{nmol} / 1$ $(0.4 \mathrm{ng} / \mathrm{ml})$ (prepubertal). There was no response of thyroid stimulating hormone, gonadotrophin, or prolactin to combined stimulation with thyroid releasing hormone and luteinising hormone releasing hormone. The table shows the plasma glucose, insulin, and growth hormone concentrations in response to an oral glucose load $(1.75 \mathrm{~g} / \mathrm{kg})$. Glucose tolerance was normal with an early, exaggerated insulin response at 30 minutes; growth hormone concentration levels were consistently low.

A large necrotic and haemorrhagic pituitary tumour that compressed the optic nerves on both sides was removed via a right frontotemporal craniotomy. Histological examination showed an acidophilic adenoma with numerous foci of calcification. Immunoperoxidase staining was positive for growth hormone and prolactin 
antibodies. His vision recovered postoperatively. He was given cranial irradiation and hormone replacement treatment with desmopressin thyroxine, and cortisone acetate. Growth was static 18 months after surgery, and plasma growth hormone and prolactin concentrations were undetectable.

\begin{tabular}{|c|c|c|c|}
\hline$\underset{(h)}{\operatorname{Time}}$ & $\begin{array}{l}\text { Glucose } \\
(\mathrm{mmol} / \mathrm{l})\end{array}$ & $\begin{array}{l}\text { Insulin } \\
(\mathrm{mU} / \mathrm{l})\end{array}$ & $\begin{array}{c}\text { Growth hormone } \\
(\mathrm{mU} / \mathrm{l})\end{array}$ \\
\hline $\begin{array}{l}0 \\
0.5 \\
1.0 \\
2.0 \\
3.0 \\
4.0\end{array}$ & $\begin{array}{l}3.8 \\
4 \cdot 7 \\
4 \cdot 0 \\
3.8 \\
3.4 \\
3.1\end{array}$ & $\begin{array}{r}9.7 \\
12.5 \\
12.1 \\
37.8 \\
33.4 \\
12.9\end{array}$ & $\begin{array}{l}1.4 \\
1.2 \\
1.2 \\
1.3 \\
1.9 \\
2.5\end{array}$ \\
\hline
\end{tabular}

\section{Discussion}

Pituitary apoplexy associated with gigantism in childhood is rare. Our patient is the youngest patient with pituitary apoplexy to have been reported on. ${ }^{3}$ Impairment of the infundibular circulation by impaction of the enlarging tumour at the diaphragmatic notch may cause infarction or haemorrhage, or both, into the pituitary gland. ${ }^{1}$ Once this process occurs the tumour mass expands beyond the site of the original adenoma and may lead to typical symptoms of raised intracranial pressure.

Previous reports of pituitary apoplexy in acromegaly have mentioned considerable improvement in clinical signs after the apoplectic episode. In most cases hypopituitarism occurs with a pronounced decrease in growth hormone concentrations. ${ }^{2}$ In our case, although plasma growth hormone concentrations were $\underline{\underline{T}}$ undetectable both before and after operation, the rapid growth, 3 tall stature and enlarged pituitary fossa substantiated the $\stackrel{\mathbb{D}}{\Omega}$ diagnosis. Galactorrhea and the results of immunoperoxidase $c$ staining indicated that it was due to a pituitary adenoma $\widehat{\triangle}$ secreting growth hormone and prolactin. A spontaneous endo- $\bar{\exists}$ crine "cure" occurred after pituitary apoplexy as hypopituitarism was present preoperatively. Growth velocity had decreased क during the previous year. During this time spontaneous de- $O$ generative changes in the pituitary adenoma such as reparative fibrosis or calcification may have occurred, which presumably arrested the activity of the adenoma.

Treatment of pituitary apoplexy requires excision of the tumour and postoperative irradiation. Recurrence may occur if $\overline{\overline{0}}$ the necrotic mass is left. ${ }^{4}$ Selective transphenoidal microsurgery $\vec{\nabla}$ in the early stage is the ideal treatment for pituitary adenoma. ${ }^{5} \Omega$ Early recognition and selective removal of adenomas offers the क⿻ best chance of preserving normal pituitary function in children $\overrightarrow{0}$ with gigantism.

\section{References}

${ }^{1}$ Sachdev Y, Copal K, Garg VK, Mongia SS. Pituitary apoplexy (spontaneous pituitary necrosis). Postgrad Med f 1981 ;57:289-93.

2 Pelkonen R, Kuusisto A, Salmi J, et al. Pituitary function after pituitary oj apoplexy. Am $\mathcal{F}$ Med 1978;65:773-8.

${ }^{3}$ Whitehead EM, Shalet SM, Davies D, Enoch BA, Price DA, Beardwell œ CG. Pituitary gigantism: a disabling condition. Clin Endocrinol 1982; $\overrightarrow{0}$ $17: 271-7$.

4 Sachdev Y, Evered DC, Hall R. Spontaneous pituitary necrosis. Br Med $\mathcal{J}$ $1976 ; \mathrm{i}: 942$

5 Quabbe HJ. Treatment of acromegaly by trans-sphenoidal operation, 90-yttrium implantation and bromocriptine: results in 230 patients. Clin Endocrinol 1982;16:107-19.

(Accepted 15 fune 1983)

\title{
Arteriovenous haemofiltration: a recent advance in the management of renal failure
}

\author{
N J DODD，R M O’DONOVAN，D N BENNETT-JONES，P B RYLANCE，M BEWICK，V PARSONS, \\ M J WESTON
}

\begin{abstract}
Twenty five patients with oliguric renal failure were treated by a combination of continuous arteriovenous haemofiltration and intermittent haemodialysis over 18 months. Haemofiltration was given for a mean of 6.6 days and the mean filtration volume was $6.01 /$ day. Fourteen of the 25 patients survived beyond two months after the period of oliguria.

Haemofiltration proved to be a simple and effective method of fluid removal; it allowed maintenance of stable

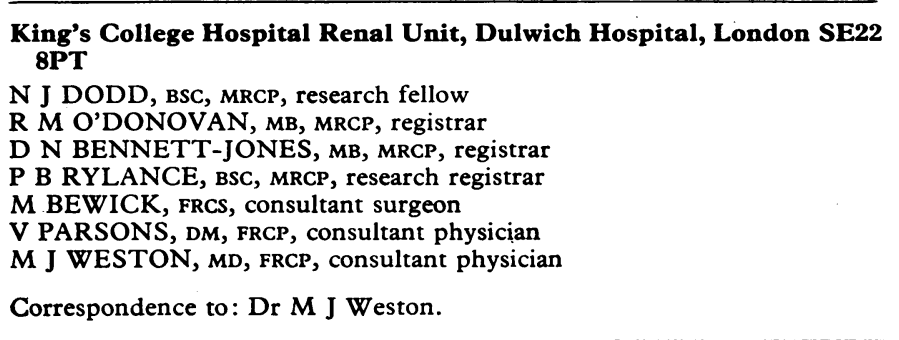

fluid balance and permitted optimum nutrition during prolonged oliguria.

\section{Introduction}

Fluid overload is a common life threatening problem in various clinical conditions. In many patients appropriate fluid restriction $N$ and treatment with diuretics will correct the abnormality, but in renal impairment such measures may be ineffective or inappropriate and dialysis may be required. Haemodialysis with ultrafiltration is efficient in removing fluids but demands skill and equipment which may not be available, and may impose $\stackrel{\mathcal{D}}{\rightarrow}$ excessive stress on the patient's cardiovascular system. Peritoneal 0 dialysis, though more readily available, may not be applicable o after abdominal surgery or trauma, and the attendant protein $\stackrel{\mathbb{D}}{\mathbb{D}}$ loss may exacerbate hypoproteinaemia and reduce tissue $\mathbb{\mathbb { D }}$ perfusion. In patients with oliguric renal failure adequate nutrition via enteral or parenteral routes is often severely restricted by the inherent fluid load. This limitation results in 8 suboptimal energy intake with exacerbation of the catabolic state or the need for frequent, often daily haemodialysis. 